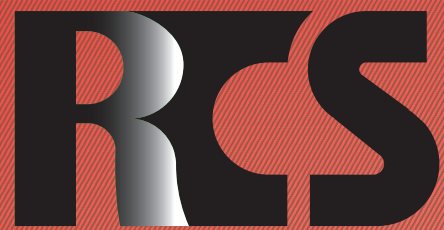

Depósito legal ppi $201502 Z U 4662$

Esta publicación científica en formato digital es continuidad de la revista impresa Depósito Legal: pp $197402 Z$ Z789

- ISSN: 1315-9518 • ISSN-E: 2477-9431

Universidad del Zulia. Revista de la Facultad de Ciencias Económicas y Sociales Vol. XXVI. No. 1

Enero-Marzo, 2021 


\section{Emergencia de las vacunas}

\section{Foladori-Invernizzi, Sofia*}

\section{Resumen}

Después de varios meses de espera llegaron las ansiadas vacunas contra la COVID-19 para la navidad del 2020. Se abrió una ventana de esperanza, con la posibilidad de salir de la pandemia y volver a la "normalidad". Pero, no hay que dejarse llevar por esa felicidad momentánea, pues la COVID-19 y otras epidemias seguirán siendo un problema de salud pública internacional, y las ansiadas vacunas deben aún demostrar su eficacia, pues llegaron bajo el paraguas de la emergencia. Las medidas de emergencia en el desarrollo de vacunas significa acelerar los ensayos clínicos y hacerlos simultáneos, dejando de lado los efectos a largo plazo que pueden surgir y que normalmente son tema de investigación durante años de evaluación de los ensayos. Las agencias gubernamentales encargadas por la aprobación de vacunas en cada país y la propia Organización Mundial de la Salud aceptan vacunas con 50\% de eficacia en los ensayos, lo cual no significa $50 \%$ cuando son utilizadas de forma masiva en toda la población, sin restricción de edades y condiciones previas. Muchas incertidumbres emergen sobre las vacunas que están siendo desarrolladas, y diversas incógnitas quedan aún por ser respondidas, enigmas que solo se sabrán después de años de la vacunación masiva.

Palabras clave: Medidas de emergencia; COVID-19; SARS-CoV-2; ensayos clinicos; vacunas.

Estudiante de Maestría en Ciencia Tecnología e Innovación en la Universidad Nacional de Rio Negro. Bióloga. E-mail: sofiafoladori@gmail.com (iD) ORCID: https://orcid.org/0000-0003-1594-957X 


\title{
Vaccine emergency
}

\begin{abstract}
After months of waiting, the longed for vaccines against COVID-19 finally arrived for Christmas. A window of hope opened with the possibility of the end of the pandemic and the return to "normality". However, we cannot be taken by this momentary happiness because COVID-19 and other pandemics will continue to pose an international public health issue and the longed for vaccines still need to prove their efficiency, as they came under the wings of emergency. The emergency measures in the development of vaccines imply speeding the process of clinical trials, and transforming successive phases into simultaneous ones, leaving unspoken the long terms effects that can arise, and are only visible after years of investigation during long-term clinical trials. Governmental agencies of each country, which are responsible for the approval of the vaccines, and even the World Health Organization, accept vaccines with $50 \%$ efficiency in clinical trials, which does not necessarily mean $50 \%$ efficiency when used in massive vaccination with no age restriction or impediment of those with previous conditions. Manny uncertainties arise about the vaccines developed, and unknowns are still to be knowns, answers that will only be available after years from massive vaccination.
\end{abstract}

Keywords: Emergency measures; COVID-19; SARS-CoV-2; clinical trials; vaccines.

Después de varios meses de espera llegaron las ansiadas vacunas contra la COVID-19 para la navidad del 2020. Cuatro países latinoamericanos (Chile, Brasil, Costa Rica y México) recibieron un primer reducido lote. Se abrió una ventana de esperanza, con la posibilidad de salir de la pandemia y volver a la "normalidad". Pero, no hay que dejarse llevar por esa felicidad momentánea, pues la COVID-19 y otras epidemias seguirán siendo un problema de salud pública mundial, y las anheladas vacunas deben aún demostrar su eficacia, pues llegaron bajo el paraguas de la emergencia.

Las vacunas contra el SARS-CoV-2 fueron hechas en tiempo récord, a juzgar por los cinco, diez y hasta más años de investigación y desarrollo de anteriores vacunas. Esto es bienvenido, pero hacer una vacuna no significa que haya pasado por los protocolos que requieren pruebas sucesivas por grupos de edades y años de monitoreo, que demuestren validez e inexistencia de resultados adversos en el largo plazo. Mientras las pruebas pueden demorar años, porque requieren de esperar potenciales reacciones biológicas en humanos que se manifiestan luego de mucho tiempo, la vacuna con pruebas de efecto a corto plazo puede hacerse en meses. Por ello, la última fase de pruebas en humanos es la más demorada. Quien determina si la vacuna está lista para inmunizar masivamente a la población no es la empresa que la produce, pero si las instituciones públicas de cada país.

Aquí es donde entran las medidas de emergencia, un tema poco divulgado. Cualquier persona podría pensar que una medida de emergencia consiste en acelerar procesos administrativos, "saltar el lugar de la fila" de vacunas en espera de ser aprobadas. También podría pensar que una medida de emergencia supone que se reúnen los fondos necesarios y los equipos científicos más rápidamente; de hecho, esto es parcialmente cierto $\mathrm{y}$ ha sido ampliamente divulgado. Una medida de emergencia puede llevar a pensar que la industria farmacéutica acelera la producción, para que no ocurra lo que está sucediendo en medio de la COVID-19, que no existe la suficiente capacidad de producción para vacunar a los millones de personas que la necesitan. Pero, no está allí la clave del estado de emergencia.

El periodo más demorado para que una 
vacuna esté disponible para su inoculación masiva, no es la investigación, sino las pruebas, particularmente las realizadas en voluntarios humanos. Esto retarda los procesos. Las pruebas deben ser secuenciales y los voluntarios monitoreados. Primero, se realizan en personas jóvenes y sanas, $\mathrm{y}$, sucesivamente, se avanza sobre otros grupos etarios de salud más frágil. Además, progresivamente aumenta también el número de voluntarios en cada fase. Entre unas etapas y otras se espera la confirmación del desarrollo de los anticuerpos, y las potenciales reacciones adversas que pueden ocurrir luego de semanas, meses o hasta años. Es necesario monitorear a los voluntarios individualmente y durante un largo periodo (World Health Organization [WHO], 2016).

Emergencia significa evadir estos plazos. Las medidas de emergencia permiten que las pruebas en humanos se realicen superpuestas o semi simultáneas en los grupos de edades; y también consiente que se reduzca significativamente el tiempo de monitoreo, suponiendo que no habrá efectos adversos visibles en el mediano y largo plazo (Singh y Upshur, 2020). Esta es una decisión política, y cada país es responsable de realizar una evaluación "costo-beneficio" según el estado de la epidemia y el riesgo de salud. Muchas veces, el costo, es lo que la economía pierde en jornadas no trabajadas, y el beneficio, lo que ahorraría de invertir en vacunas. En un sistema capitalista la salud se mide en dinero. Indonesia, por ejemplo, negoció la vacuna Rusa y China, con base en las pruebas hechas en Medio Oriente y en América del Sur, y antes de la autorización de emergencia en los propios países productores (Singh y Upshur, 2020).

De igual manera, emergencia también tiene que ver con el criterio políticoadministrativo de determinar cuándo una vacuna es eficiente. La Organización Mundial de la Salud, por ejemplo, considera que una vacuna está pronta cuando el $50 \%$ de los inoculados en las pruebas de ensayos clínicos, desarrollaron los anticuerpos; pero cada país toma el criterio que considera más apropiado
(Singh y Upshur, 2020).

En los Estados Unidos, por ejemplo, la FDA, que es la agencia gubernamental encargada, aprueba un medicamento aceptando apenas dos procesos de prueba que ofrezcan $50 \%$ de eficacia. Esto significa que aunque los medicamentos hayan pasado por otros procesos de prueba, y aunque estos hayan tenido resultados negativos, los mismos no entran en los criterios para aprobación, dado que no todos los resultados y ensayos realizados deben ser publicados por las empresas que los realizan (Angell, 2005). En el caso de las vacunas aprobadas por procedimientos de emergencia, sería oportuno conocer los resultados completos de todas las pruebas realizadas, considerando que no es posible obtener los resultados de efectos a largo plazo pues estos no son requisito bajo medidas de emergencia.

En la Unión Europea, la Agencia Europea de Medicamentos (EMA) y en Reino Unido, la Agencia Reguladora de Medicamentos y Productos para la Salud (MHRA), aprueban vacunas para la COVID-19 con menos de 50\% de eficacia. Estos porcentajes son menores que los exigidos por los mismos países respecto a la vacuna de la gripe (Singh y Upshur, 2020).

Ahora bien, ¿qué sucede si un país no tiene una agencia regulatoria de medicamentos? En América Latina, por ejemplo, los gobiernos podrían consultar a expertos de la Organización Panamericana de la Salud, y, conjuntamente determinar un porcentaje "razonable" de eficacia de la vacuna (Singh y Upshur, 2020), pero este no necesariamente debe llegar al 50\%. Lo lógico es que la eficacia sea un alto porcentaje, puesto que no hay forma de dar seguimiento individual a los inoculados, y porque los voluntarios de las pruebas, no manifestarán en el corto plazo resultados adversos que podrían manifestar en el mediano y largo plazo.

Las autoridades sanitarias de los países se encuentran en una encrucijada frente a la COVID-19. Con miles de enfermos y muertes, deben tomar decisiones de emergencia en un contexto donde las presiones capitalistas mundiales, han desmantelado los sistemas 
públicos de salud desde los años ochenta en que se impuso el neoliberalismo; y donde el $80 \%$ de las ventas de vacunas está concentrada en media docena de grandes corporaciones, que no asumen ninguna responsabilidad sobre el producto, y que sólo producen vacunas cuando existe mercado, o sea epidemia, como ha sido constatado con el anterior virus COVSARS en 2017 (Boffey, 2020), dejando a las autoridades sanitarias de cada país con el peso de la responsabilidad.

El negocio de las vacunas no parece responder al concepto de "evidencia científica", a juzgar por las incertidumbres que la vacunación no contempla. No se sabe el efecto de las vacunas en los ancianos, y otras franjas etarias, en aquellos con enfermedades previas, frente a cepas más agresivas del virus, durante el periodo de inmunización, en la cantidad y periodicidad necesaria de revacunación, en la severidad de la reinfección, y otras incógnitas. Además, queda por saber si las vacunas apenas reducen la gravedad de la enfermedad o si impiden la transmisión del virus (The Lancet, 2020).

Aunque, se debe tener esperanza en que las vacunas actúen eficientemente y los efectos adversos sean mínimos, el problema de fondo no son las vacunas, ni las decisiones políticas. El problema, es que muchas de las epidemias que han brotado en las últimas tres décadas son de origen zoonótico, resultado de la expansión de la agricultura de monocultivo, de la destrucción de los bosques, del confinamiento de la producción animal y de la generalización de químicos tóxicos en el ambiente. El problema no es sólo de salud, es civilizatorio.

\section{Referencias bibliográficas}

Angell, M. (2005). The truth about the drug companies: How they deceive us and what to do about it. Random House.

Boffey, D. (2020, May 25). Exclusive: Big pharma rejected EU plan to fast-track vaccines in 2017. The Guardian. https://www.theguardian.com/ world $/ 2020 / \mathrm{may} / 25 /$ exclusive-bigpharma-rejected-eu-plan-to-fast-trackvaccines-in-2017

Singh, J. A., y Upshur, R. E. G. (2020). The granting of emergency use designation to COVID-19 candidate vaccines: Implications for COVID-19 vaccine trials. The Lancet Infectious Diseases. https://doi.org/10.1016/S14733099(20)30923-3

The Lancet (2020). Editorial. COVID-19 vaccines: No time for complacency. The Lancet, 396(10263), P1607. https://doi.org/10.1016/S0140$\underline{6736(20) 32472-7}$

World Health Organization - WHO (2016). Guidelines on clinical evaluation of vaccines: Regulatory expectations. WHO. $\quad$ https://www.who.int/ biologicals/expert committee/ Clinical changes IK final.pdf 